Start typingon his line 50

\section{A Model for the Control of Dissolved Manganese in the Interstitial} Waters of Chesapeake Bay

G. R. Holdren, Jr., O. P. Bricker, III, G. Matisoff.

Department of Earth and Planetary Sciences, The Johns Hopkins University, Baltimore, Md., 21218

Recent interest in the origin of marine and fresh water ferro-manganese deposits has resulted in a number of investigations of the distribution of dissolved manganese in recent sediments $(1-6)$. Attempts to model the observed manganese distribution have been made by several investigators.

Michard (7) devised a model to describe the concentration of manganese as a function of depth in the sediment by dividing the sediment into three chemically distinct zones and by using a partition coefficient, $\alpha$, to describe the distribution of manganese between the solid and solution phases. The differential equations were developed independently for each zone, and, then, they were coupled at the boundaries between the different zones in order to maintain continuity in the calculated profiles. Calvert and Price (8) developed a qualitative model to describe the profiles of manganese in the sediments of Loch Fyne, Scotland. Unfortunately, their sample spacing was too large to delineate the fine structure of the dissolved manganese profile typically found in the top few centimeters of an estuarine sediment. IAlso, analyses of chemical parameters other than the trace metals were not done, and so, they could only presume that the chemical controls in Loch Fyne were the same as have been found in other systems. Robbins and Callendar (9) developed a model, purportedly continuous over the depth of the sediment column, to describe the diagenesis of manganese in Lake Michigan sediments. This model, however, requires that a point source of manganese exist at some arbitrary depth in the sediment and that the concentration of dissolved manganese slowly approach equilibrium with solle elusive detrital manganese phase at greater depths. While a rice qualitative fit is obtained for their field data, very little is actually known about the chemical nature of these interstitial waters, and, thus, the operative equilibrium controls in this systen are again left to conjecture. observed enrichment of manganese in the solid phases of surface sediments. Bender (10), Anikonchine (11), and Lynn and Bonatti
This report was prepared as an account of work sponsored by the United States Government. Neither Research and Development Administration, nor any of their employees, nor any of their contractors, subcontractors, or their employees, makes any warranty, express or implied, or assumes any legal or usefulness of any information, apparatus, product process disclosed, or represents that its use would not infringe privately owned rights.
intecess disclosed, or represnts

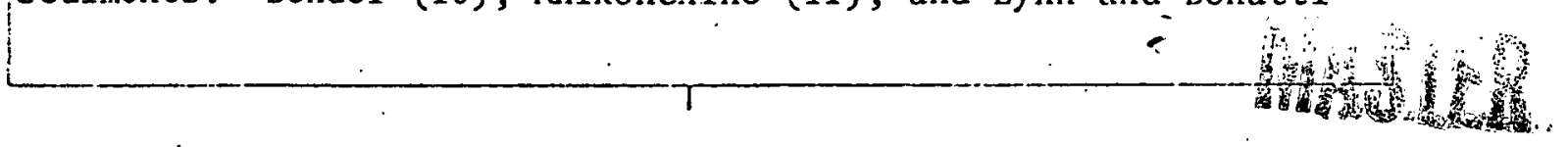




\section{DISCLAIMER}

This report was prepared as an account of work sponsored by an agency of the United States Government. Neither the United States Government nor any agency Thereof, nor any of their employees, makes any warranty, express or implied, or assumes any legal liability or responsibility for the accuracy, completeness, or usefulness of any information, apparatus, product, or process disclosed, or represents that its use would not infringe privately owned rights. Reference herein to any specific commercial product, process, or service by trade name, trademark, manufacturer, or otherwise does not necessarily constitute or imply its endorsement, recommendation, or favoring by the United States Government or any agency thereof. The views and opinions of authors expressed herein do not necessarily state or reflect those of the United States Government or any agency thereof. 


\section{DISCLAIMER}

Portions of this document may be illegible in electronic image products. Images are produced from the best available original document. 
Start typingron us line

Start first page on this line
(12) have developed diffusion models to describe this phenomona. The emphasis of these works has been to investigate if upward diffusion of manganese could supply the metal required to explain the observed enrichment. In light of this goal, no attempts were made to describe the specific diagenetic reactions involved in the control of manganese in these sediment systems.

In this paper, we explore possible chemical and physical mechanisms that may control the distribution of manganese in the Chesapeake Bay estuarine sediments. Interstitial waters of the bay sediments contain greater concentrations of dissolved manganese than have been reported in any other marine or brackish water sediment system $(1-4)$. It is not uncommon to find manganese concentrations that exceed $400 \mu \mathrm{M}(\sim 20 \mathrm{ppm})$ and concentrations as high as $950 \mu \mathrm{M}(52.5 \mathrm{ppm})$ have been observed. Based on these observations and the general chemical composition of the interstitial waters, we develop a model to describe profiles of manganous ion in the Chesapeake Bay sediments.

\section{Field Study and Methods}

A two phase field program was initiated to investigate the spatial and temporal variability in the pore water composition of Chesapeake Bay sediments. Figure 1 shows the location of some of our standard sampling stations. The problems involved in relocating at any particular stations in the bay and the attendant sampling errors have been discussed (13).

Temporal changes were investigated by sampling monthly at a mid-bay station for the period June 1971 to August 1972. This station, $858-8$, is located at $38^{\circ} 58^{\prime} 20^{\prime \prime} \mathrm{N} \times 76^{\circ} 23^{\prime} \mathrm{W}$, east of the mouth of the Severn River and is located in about $33 \mathrm{~m}$ of water. Three gravity cores were collected each month using a Benthos gravity corer. The sediment was held in cellulose-acetatebutyrate plastic coreliners. A plastic butterfly valve was used to retain the sediment during retrieval. The water trapped above the: sediment in the core liners during this operation was siphoned off, filtered and saved for chemical analysis. Predetermined sections of the sediment were extruded directly into Reeburgh-type sediment squeezers (14). The pore waters to be used for chemical analysis were expressed through whatman filter paper and $0.22 \mu \mathrm{m}$ Millipore membrane filters by 150 psi pressure exerted by nitrogen gas against a rubber diaphram in the squeezer. Aliquots of these samples were analyzed for carbonate alkalinity, chloride, ammonia, reactive phosphate, ferrous iron, pH, $\mathrm{ps}=$ and Eh onboard ship. The remainder of the sample was returned to the lab for analysis of silica and sulfate. A complete description of both the analytical techniques and the sample handling procedures are found elsewhere in this symposium (13). ability of the pore water composition in the bay was investigated. 


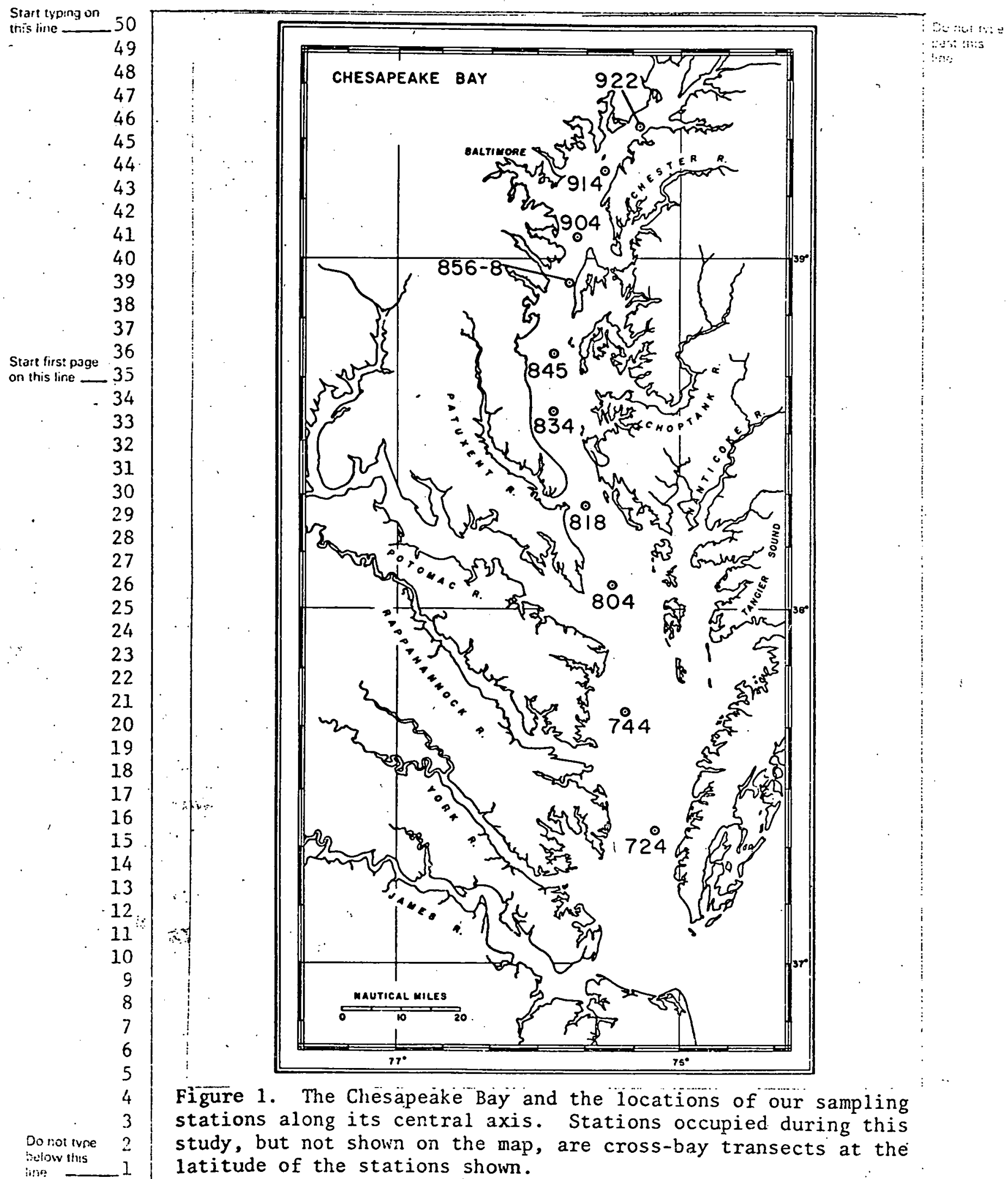


Type Single Spaced Only

Do Not Type on This Line

jtart typing on Inis line 50

49

48

47

46

45

44

43

42

41

40

39

38

37

Stant first page on this line 35

\section{Six cruises conducted between August 1972 and December 1974 allowed us to collect over 700 individual interstitial water} samples along with the associated sediment. Sampling locations ranged from station 935 , located at the mouth of the Susquehanna River near Havre de Grace, Md., to station 724R, located bétween the York and Rappahannock Rivers in Virginia. During this phase of the program, all sample handling operations were done in a glove box under an inert nitrogen atmosphere to avoid the loss of trace metals and phosphate (15). Otherwise, all onboard and laboratory analytical techniques remained unchanged. In addition to the above analyses, dissolved manganese was determined on acidified subsamples of the pore water collected during this phase of the study by direct aspiration of the sample into an atomic absorption spectrophotometer. Typically, samples were diluted by a factor of between 5 and 100 with 0.01 NHC1 to lower the concentration of manganese into the linear range of detection for our instrument. A detail description of the techniques is found elsewhere in this symposium (13).

Results and Discussion

Physical Influences on Transport: Chloride Data. The Chesapeake Bay estuary is a very productive area, biologically. This is reflected in the organic content of the sediments in the estuary which is typically 2 to $3 \%$ on a dry weight basis. A large infaunal benthic community is supported by these organics. The resulting activity mixes the upper portion of the sediment and enhances the exchange of material between the sediments and the overlying water. To investigate the magnitude of this mixing effect, along with other physical processes such as diffusion, we have studied the time dependent changes that occur in pore water chloride concentration with depth beneath the sediment/water interface.

Chloride is an ideal tracer to study these effects in an estuary such as the bay. It is essentially inert in terms of chemical reactivity in the estuarine environment. Thus, only the changing physical environment affects its distribution. Because of the seasonal variations in the fresh water input to the bay, the chloride distribution in the bottom waters is constantly changing. This produces a continually varying concentration gradient between bottom waters and interstitial waters. By following the response of the chloride profile in the sediment to changes in the chlorinity of the overlying waters, an estimate of the net rate of transport in the sediment can be made.

Figure 2 shows the results of our study at station 858-8. Easily measurable changes occur in the chloride profile on a month-to-month basis. The surface sediments respond most quickly and, with increasing depth, the magnitude of the changes decreases until at a depth of about $20 \mathrm{~cm}$, variations are essentially within the analytical limits of the measurements. The mean concentration 


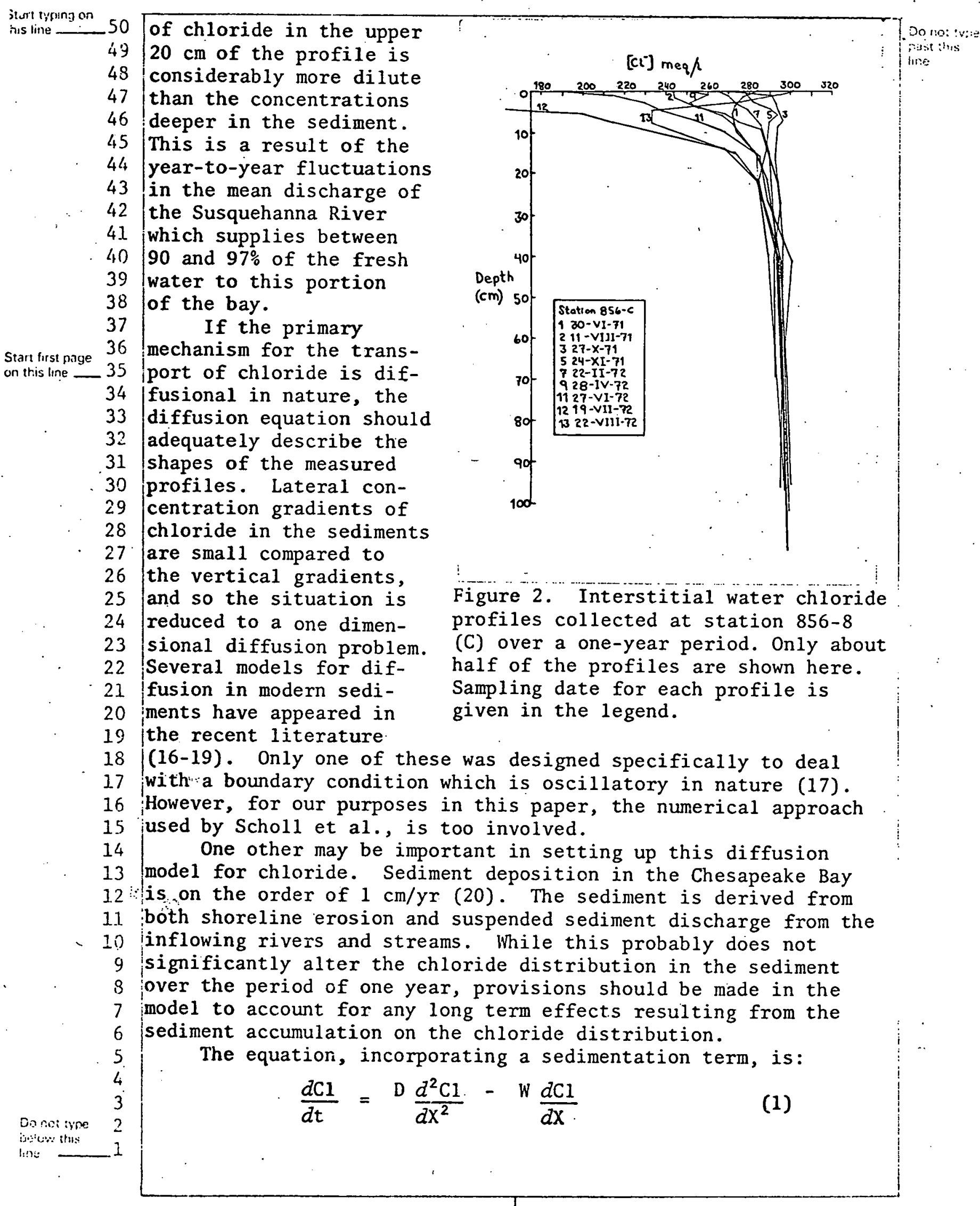


Start ryping on hiș lune on this lune

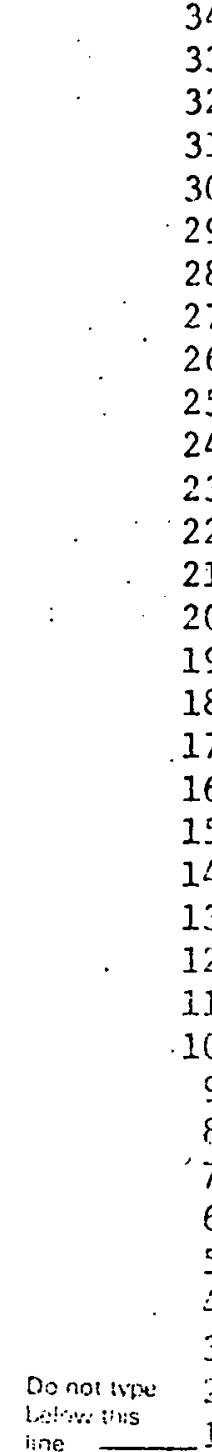

With the boundary conditions:

$$
\begin{aligned}
\mathrm{Cl}(0, t) & =\mathrm{Cl}_{0}+\mathrm{Cl}_{1} \cos (\lambda, t)+\mathrm{Cl}_{2} \cos \left(\lambda_{2} \mathrm{t}\right) \\
\left.\frac{\mathrm{dCl}}{\mathrm{dX}}\right|_{X \rightarrow \infty} & =0
\end{aligned}
$$

Equation ( 1 ) is the standard one-dimensional form of the diffusion equation with an advective term $(-W d C 1 / d X)$ to describe the effects of sediment deposition. The boundary conditions are based on the physical observation made for the system.

The first boundary condition describes the chloride concentration in the overlying water as a function of time. The first term on the right hand side of the equation is the long term mean chlorinity. The second term accounts for the seasonal fluctuations in the chloride concentration. These are the variations observed in the month-to-month changes in the chloride profiles. The last term describes the long term changes in the mean annual chlorinity. It is this term which accounts for the skewing of the upper portion of the profile toward more dilute concentrations relative to the deeper pore waters.

The second boundary condition simply states that there is no net diffusional flux of chloride at great depth in the sediment. This is equivalent to saying that the estuary is "lined" by impermeable bedrock beneath the sediment.

For constant $D$ and.W the solution to this equation is found in Carslaw and Jaeger (21):

$C 1(x, t)=C 1_{0}+C 1_{1} \cos \left\{\lambda_{1} t-X a_{1}^{\frac{1}{2}} \sin \frac{1}{2} \phi_{1}\right\} \exp \left|\frac{W X}{2 D}-X a_{1}^{\frac{1}{2}} \cos \frac{1}{2} \phi_{1}\right|$ $+\mathrm{Cl}_{2} \cos \left\{\lambda_{2} t-\mathrm{Xa}_{2}{ }^{\frac{1}{2}} \sin ^{\frac{1}{2}} \phi_{2}\right\} \exp \left|\frac{\mathrm{WX}}{2 \mathrm{D}}-\mathrm{Xa}_{2}{ }^{\frac{1}{2}} \cos \frac{1}{2} \phi_{2}\right|$

where $a_{1}=\left|\frac{W^{4}}{160^{4}}+\frac{\lambda i^{2}}{D^{2}}\right|^{\frac{1}{2}}$

and $\quad \phi_{1}=\tan ^{-1}\left(4 D \lambda i / W^{2}\right)$

By picking values for $W, D$, and $\lambda_{2}\left(\lambda_{1}=2 \pi /\right.$ year $)$, theoretical, time dependent chloride profiles can be calculated. The range of the values for. $W$ and $\lambda_{2}$ are available from independent sources $(20,22)$. Therefore, an estimate of the diffusion coefficient typical of bay sediments can be made by matching calculated profiles to the field data.

The results of some representative calculations are shown in figure 3a-c. All three parameters, D. W and $\lambda_{2}$, were varied in the calculations to determine the net effect of each on the profiles. Results indicate that reasonable rates of sedimentation has very little effect on the chloride profiles. It makes little difference whether $W$ is $3 \times 10^{-5} \mathrm{~cm} / y \mathrm{r}$ or $3 \mathrm{~cm} / \mathrm{yr}$ in the final results. Changes in $\lambda_{2}$ has only a slightly greater effect. 





Start typung on thes line

Siart furst paye on this line

Do not ive Somiow atis ials?
Changes in the diffusion coefficient, $D$, had the greatest
effect of these three parameters. Comparison of the calculated
profiles to the field data indicate that the best value for a
constant $D$ is $5 \times 10^{-6} \mathrm{~cm}^{2} / \mathrm{sec}$. This is in good agreement with
values that have been reported in other sediment systems $(23,24)$
Results of the model indicate that the diffusion coefficient is
not strictly a constant with depth. We have a numerical model
which calculates chloride concentration profiles through time for
any arbitrary functional form of $D$. However, the purpose here is
not to generate exact replicates of the observed chloride pro-
files in the bay sediments, but rather is to obtain a feeling
for the magnitude of the combined effects of diffusion, brotur-
bation and sedimentation on the distribution of any dissolved
component of the interstitial waters. The simple model described
above accomplishes this goal.

Manganese: Field Data. The next step in determining the overall diagenetic behavior of dissolved manganese in anoxic pore waters is to identify which, if any, specific reactions or apparent equilibria may be involved in controlling the manganese cycle. To do this it first helps to examine the concentration profiles of manganese. Figure 4 shows some typical profiles of dissolved manganese for stations located along the axis of the bay. These samples were collected in the summer of 1973 .

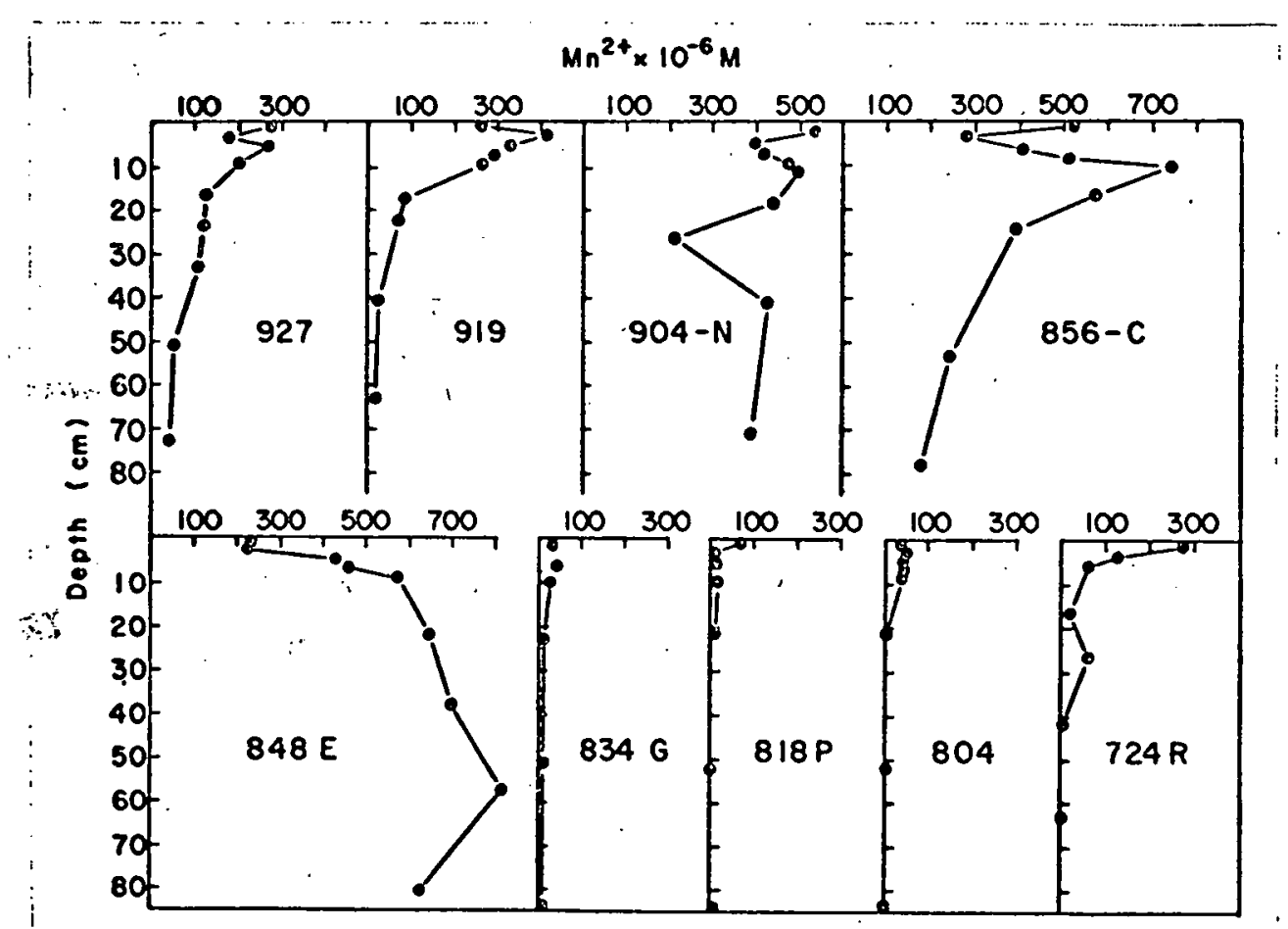

Figure 4. Profiles of dissolved manganese in the interstitial waters of the sediments obtained along the central axis of the bay. These are typical sumner profiles. 


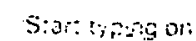
$\because \because 30$

49

48

47

46

45

44

43

42

41

40

39

38

37

Stort firs: page 36
on ihis the 35

34

33

32

31

30

29

28

27

26

25

24

23

22

21

20

- 19

18

17

16

15

14

13

12

11.

10 1.
Several features of these profiles should be noted. The concentration of dissolved manganese in the overlying waters never exceeded $6 \mu \mathrm{M}$ on this cruise. These values, which are relatively concentrated by open water standards, are probably the result of the resuspension and subsequent mixing of the top few millimeters of sediment which occurred during the coring operation. Within the sediment, concentrations of dissolved manganese increase quickly below the sediment/water interface. Commonly, the concentration in the top two centimeters of the sediment column is the highest in the core. Concentration of dissolved manganese usually decreases with depth. Samples collected at other times of the year exhibit the same gross features. However, during colder periods, the maximum concentration is reached five or ten centimeters below the sediment/water interface.

To determine whether any heterogeneous equilibrium constraints are being imposed on the concentration of dissolved manganese by the pore water composition, activity calculations were made on each sample. These calculations were checked for possible saturation of a number of common sedimentary manganese minerals including rhodochrosite $\left(\mathrm{MnCO}_{3}\right)$, reddingite $\left(\mathrm{Mn}_{3}\left(\mathrm{PO}_{4}\right)_{2}\right.$. $3 \mathrm{H}_{2} \mathrm{O}$ ) and albandite ( $\mathrm{MnS}$ ). The calculation used a modified form of the Garrels and Thompson model for sea water (25) to describe the ionic medium and determine ionic strengths. Activity coefficients were estimated from the extended form of the Debye-Hückel equation. An ion pairing model was then used to calculate activities of manganous ion from the composition of the pore waters. Free energy data used in calculations were obtained from several sources $(26,27)$.

The results of these calculations indicate that rhodochrosite is the only mineral for which the pore waters exceed saturation. This supersaturation exists at all stations and for most levels within the sediments of the bay. In the northern bay, the pore waters are between 1.5 and 2.5 orders of magnitude supersaturated and in the southern bay, the pore waters are generally in the range of 0.5 to 1.5 orders of magnitude supersaturated with respect to rhodochrosite.

Alabandite is the only other mineral that even approaches saturation in the pore water system. This situation occurs in the southern portion of the bay where pore water sulfide values are generally higher because of the greater sulfate concentrations in the overlying water.

To describe manganese profiles in the bay, the interaction between manganese and carbonate must be further investigated. To this end it is helpful to understand the behavior and genesis of bicarbonate in the pore waters of the bay.

Carbonate. At pore water pH's, bicarbonate ion concentration is essentially equal to the carbonate alkalinity. Figure 5 shows
Du noi tyits: p.15i this 


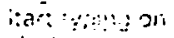
wis !iji:

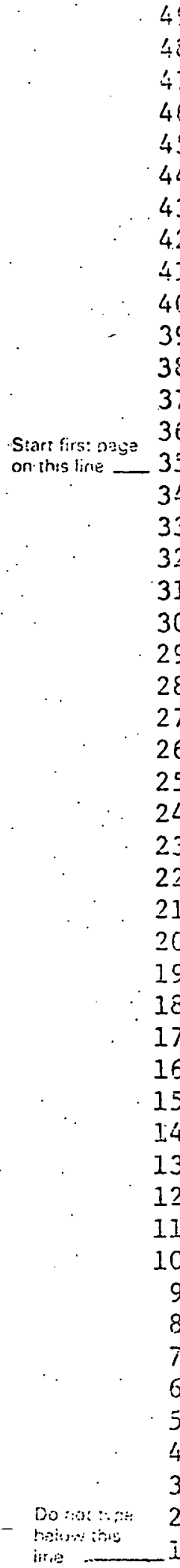

located along the axis of the bay. Concentrations of bicarbonate ion in surface sediments and overlying waters rarely exceed 1.5 meq/1. The concentration generally increases with depth; however; individual profiles can be quite complex. i
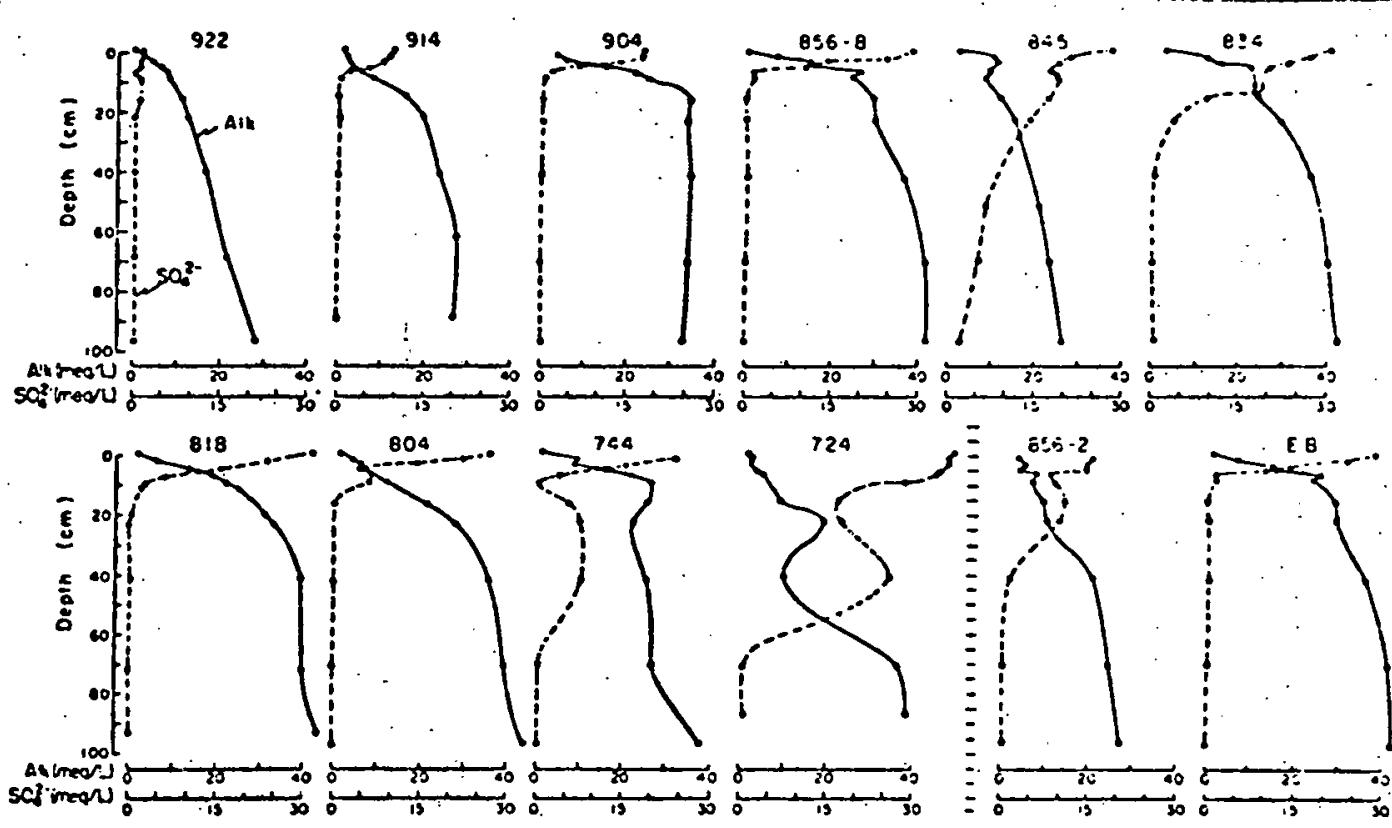

Figure 5. Sulfate and alkalinity data for the interstitial waters along the axis of the bay. These are typical profiles.

Bicarbonate ion is a byproduct of bacterial oxidation of organic matter in the sediment. In an anoxic marine environment, sulfate is used by the bacteria as an oxygen source. The general equation for this oxidation is written:

$$
\begin{gathered}
\left(\mathrm{CH}_{2} \mathrm{O}_{106}\left(\mathrm{NH}_{3}\right)_{16}\left(\mathrm{H}_{3} \mathrm{PO}_{4}\right)+53 \mathrm{SO}_{4}{ }^{2}=106 \mathrm{HCO}_{3}^{-}+53 \mathrm{HS}^{-}\right. \\
+16 \mathrm{NH}_{4}^{+}+\mathrm{HPO}_{4}{ }^{2-}+39 \mathrm{H}^{+}
\end{gathered}
$$

For every equivalent of sulfate reduced, one equivalent of bicarbonate is generated, along with lesser amounts of ammonia, phosphate and sulfide. Measured profiles of sulfate in the bay sediments are shown in figure 5 . The one-to-one correspondence between the amount of sulfate reduced and the amount of bicarbonate generated as predicted by (5) does not hold true. However, as can be seen in figure 5, a nearly linear relation does exist.

Bicarbonate Ion Control of Manganese. The reaction of bicarbonate ion with manganous ion can be expressed as:

$$
\mathrm{Mn}^{2+}+\mathrm{HCO}_{3}^{-}=\mathrm{MnCO}_{3}(\mathrm{~S})+\mathrm{H}^{+}
$$

Du nisi vos peist this line 
Sic: $: 2=0$ on ถ⿻: $3:$ : :
As indicated by the activity calculations, this is the reaction which controls the concentration of manganese in the sediment. The ion activity product (IAP) of the reaction components of (6) calculated from pore water compositions usually exceeds the thermodynamically derived solubility product of rhodochrosite. This occurs for two reasons.

First, one of the assumptions made in setting up the ion pairing model to calculate manganous ion activities was that only inorganic ion pairs need be considered. No attempt was made to account for organic complexes of manganese. The interstitial waters of the Chesapeake Bay contain up to $70 \mathrm{ppm}$ dissolved organic carbon. Others (28) have shown that manganese can complex strongly with naturally occurring organics. Because the association constants for reactions of this type are not well known, they cannot be included in the equilibrium calculations. This exclusion results in calculated activities which are larger than actually occur.

The second reason apparent supersaturation exists in the bay sediments is that the IAP we calculate is compared to the solubility of pure rhodochrosite. It is highly likely that the rhodochrosite in the sediments is not a pure phase, but a solid solution with an enhanced solubility compared to that of pure rhodochrosite.

To incorporate the effects of these two factors, we calculated an "apparent stability constant", $K_{S}^{\prime}$, to describe the reaction between the dissolved components and the solid sedimentary carbonate phase. $\mathrm{pH}$, alkalinity and manganese data from the deepest sample from each core was used for this purpose. We felt that. these samples had had the greatest opportunity to attain equilibrium with the solid phase. This calculation yields a Gibbs free energy for the manganese carbonate phase of $-193.1 \mathrm{kcal} / \mathrm{mole}$. These combined effects reduce the apparent stability of the sediment phase by about $2 \mathrm{kcal}$ compared to the free energy of pure rhodochrosite which lies in the range -195.05 (29) to -195.7 $\mathrm{kcal} / \mathrm{mol}(30)$.

If the $\mathrm{pH}$ and bicarbonate concentration are known, the concentration of manganese can be determined from the mass action relation for (6).

$$
\because \mathrm{Mn}^{2+}=\frac{\mathrm{Ksp}_{\mathrm{S}} \cdot\left[\mathrm{H}^{+}\right]}{\left[\mathrm{HCO}_{3}^{-}\right]}
$$

Sample by sample adjustments of $\mathrm{pH}$ could be made in applying (7) to the calculated manganese profiles. However, because variations in $\mathrm{pH}$ with depth in any one core are generally smal1, and in order to maintain continuity, the mean value of the measured $\mathrm{pH}$ within a core is used for all depths in that core.

Similarly, bicarbonate concentrations on a point by point basis could be used in the calculation. However, to expedite the computational process and again for sake of continuity in the 


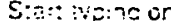

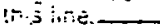

Stari iirst cage on this ine

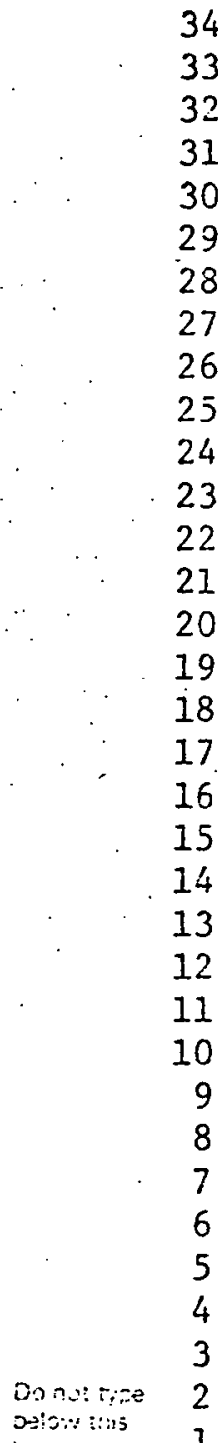

ine profiles, we chose to use a simple model to describe the generation of bicarbonate. Because of the observed relation between sulfate and bicarbonate, a modification of Berner's model for sulphur diagenesis was used (31) to calculate the bicarbonate distribution in the sediment. Bicarbonate concentration is described as a function of depth by the equation:

$$
\mathrm{HCO}_{3}^{-}=\mathrm{HCO}_{3}^{-}(\mathrm{I})+\frac{W^{2} \mathrm{G}_{0}}{W^{2}+\mathrm{K}_{1} \mathrm{D}}\left[1-\exp \left(-\mathrm{K}_{1} \mathrm{X} / \mathrm{W}\right)\right]
$$

where $\mathrm{HCO}_{3}^{-}(\mathrm{I})=$ bicarbonate in the overlying water

$\mathrm{W}=$ the sedimentation rate

D = the diffusion coefficient for bicarbonate

$G_{o}=$ the organic content of surface sediments

$K_{1}=$ the first order rate constant for bicarbonate generation

and $\mathrm{X}=$ distance below sediment/water interface $(\mathrm{cm})$

There are several assumptions in this model. W and D must be constants through time and space, respectively. Generation of bicarbonate is assumed to be a first order reaction with respect to the amount of available organic material in the sediment.

Finally the bicarbonate profile is assumed to have reached steady state. Since we are simply fitting this model to the bicarbonate data, these assumptions are of little concern to us.

Estimates for $W$ and $D$ are obtained by independent means. By adjusting the values of $K_{1}$ and $G_{0}$ the model can be fit to the data. The results of this method of calculating the bicarbonate concentrations are shown in figure 7 for several of our stations. The values of $\mathrm{pH}, W, K_{1}$, and $G_{0}$ used for each station are listed in table $\mathrm{I}$.

Station

$\because$ TABLE I

904D

$834 \mathrm{G}$

1.0

7.5

0.0133

0.091

0.0173

0.010

$914 \mathrm{Q}$

0.5

7.65

0.0385

0.265

0.0173

0.0025

$848 \mathrm{~F}$

1.0

7.2

0.0345

0.082

0.0173

0.012

$919 \mathrm{~T}$

1.0

7.7

0.0198

0.179

0.0173

0.005

7.0

0.0277

0.105

0.0173

0.015

\section{$D=3 \times 10^{-6} \mathrm{~cm}^{2} / \mathrm{sec}$. for all stations.}

By using (8), concentrations of dissolved manganese can be calculated for most of the sediment column. However, the results of the calculation in the top few centimeters of the sediment are inconsistent with the field data. This portion of the profile must be controlled by some other process.
Do nistrye past tivis

ine 
S:art :yrita on th: in:? 50 Oxidation and Diffusion of Manganese. The concentration of
dissolved manganese in the waters immediately overlying the sedi-
ment are generally small. The concentration jumps to as high as $857 \mu \mathrm{M}$ within the top two centimeters of the sediment. To maintain such a large concentration gradient over a small distance for any length of time, a sink for dissolved manganese must exist at the sediment/water interface. Manganese is sensitive to the oxidation potential of the environment. Upon diffusing from the anoxic mud into a zone containing free molecular oxygen, manganese would precipitate as a hydrous-oxide phase. Then, upon burial, this metal would be available for remobilization. The concentration of dissolved manganese in the zone immediately beneath the oxic layer is dependent on two factors: 1) how fast the metal is released from the solid phase, and 2) how quickly it diffuses away from its source. The rate a material is released from a solid depends on many parameters. The surface area of the solid is one of the major factors $(32,33)$. The hydrous oxide phase is present essentially as a two dimensional coating on clay particles. For this reason, the amount of solid manganese is roughly proportional to the surface area of the solid available for dissolution. If we assume that the rate of dissolution of manganese is first order relative to the amount of avai1able solid phase, the rate of production will be expressed as

$$
\frac{d \mathrm{Mn}^{2+}}{d \mathrm{t}^{-}}=-\mathrm{K}_{2}\left(\mathrm{MnO}_{2}\right)
$$

To apply this expression to bay sediments, we must assume that for any station the supply of solid manganese to the surface sediments is constant with time. Since this surface zone rarely extends more than about $5 \mathrm{~cm}$ into the sediment, representing a. maximum period of about 10 years, this is a reasonable assumption. Finally, the balance between the rate of dissolution and subsequent upward diffusion of the manganous ion must be established. If we assume the system is in steady state, this balance can be written

$$
\text { D } \frac{d^{2} \mathrm{Mn}^{2+}}{d \mathrm{X}^{2}}-\mathrm{W} \frac{d \mathrm{Mn}^{2+}}{d \mathrm{X}}+\mathrm{K}_{2}\left(\mathrm{MnO}_{2}\right)=0
$$

with the boundary conditions

and

$$
\mathrm{Mn}^{2+}(0, \mathrm{t})=0
$$

The solution to this equation is

$$
\mathrm{Mn}^{2+}=\frac{\mathrm{W}^{2}\left(\mathrm{MnO}_{2}\right)_{0}}{W^{2}+\mathrm{K}_{2} \mathrm{D}}\left[1-\exp \left(-\mathrm{K}_{2} \mathrm{X} / \mathrm{W}\right)\right]
$$


i: $: 2: \because 30 \%$ on $\therefore 50$

13

12

11

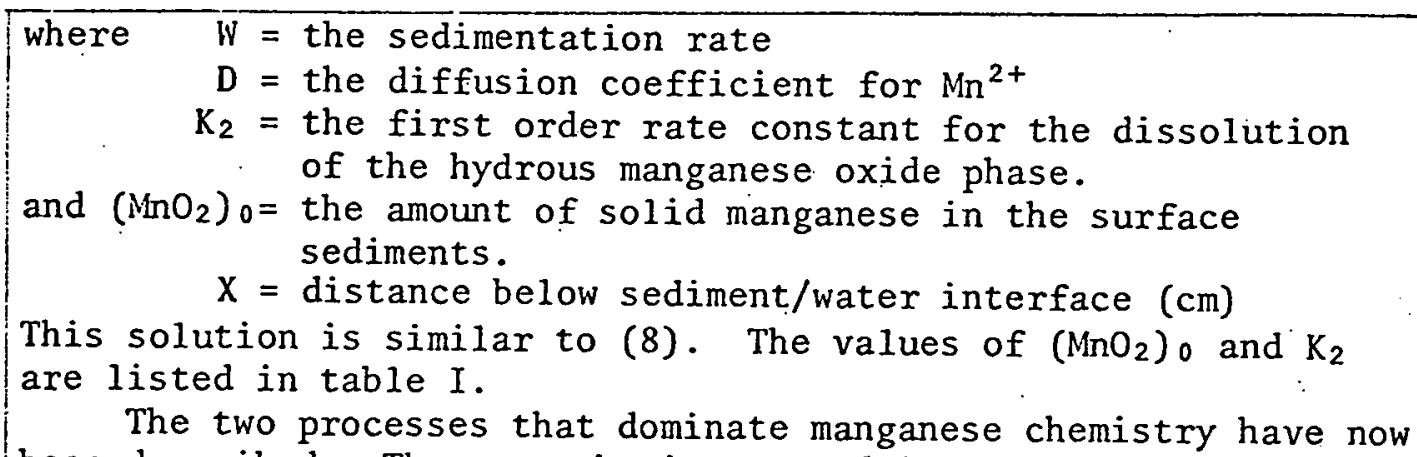
depths, the amount of dissolved $\mathrm{Mn}^{2+}$ which can be maintained by dissolution is greater than that which is allowed by the solubility of the manganese carbonate. Precipitation of the carbonate then becomes the limiting factor in the observed concentration of the metal. Therefore, by calculation the concentration of manganese using both (7) and (11), the observed concentration will be the lesser of the two values at any particular depth.

Results of Model Calculations. Figure 6 shows the results of our calculations: The second in each set of graphs shows the concentration of dissolved manganese as a function of depth in the sediment at several northern and mid-bay stations.

The solid line is the concentration of dissolved manganese predicted by the model. Remember that this single line is the combined result of two competing processes. The portion of the curve increasing with depth is the result of the dissolution and upward diffusion of manganous ion. The lower portion of the profile is the part controlled by equilibrium with the carbonate phase.

\section{Conclusion}

We have developed a model for the prediction of dissolved manganese distribution in the anoxic pore waters of the sediments of the Chesapeake Bay. The model requires knowledge of the $\mathrm{pH}$ of the pore waters, the distribution of bicarbonate ion with depth in the sediment, the amount of manganese oxide in the surface sediment and the rate of release of manganous ion from those solids. In the calculations presented, a modification of Berner's model for sulphur diagenesis was used to describe bicarbonate ion distribution. This model was fit to the observed profiles. Other 


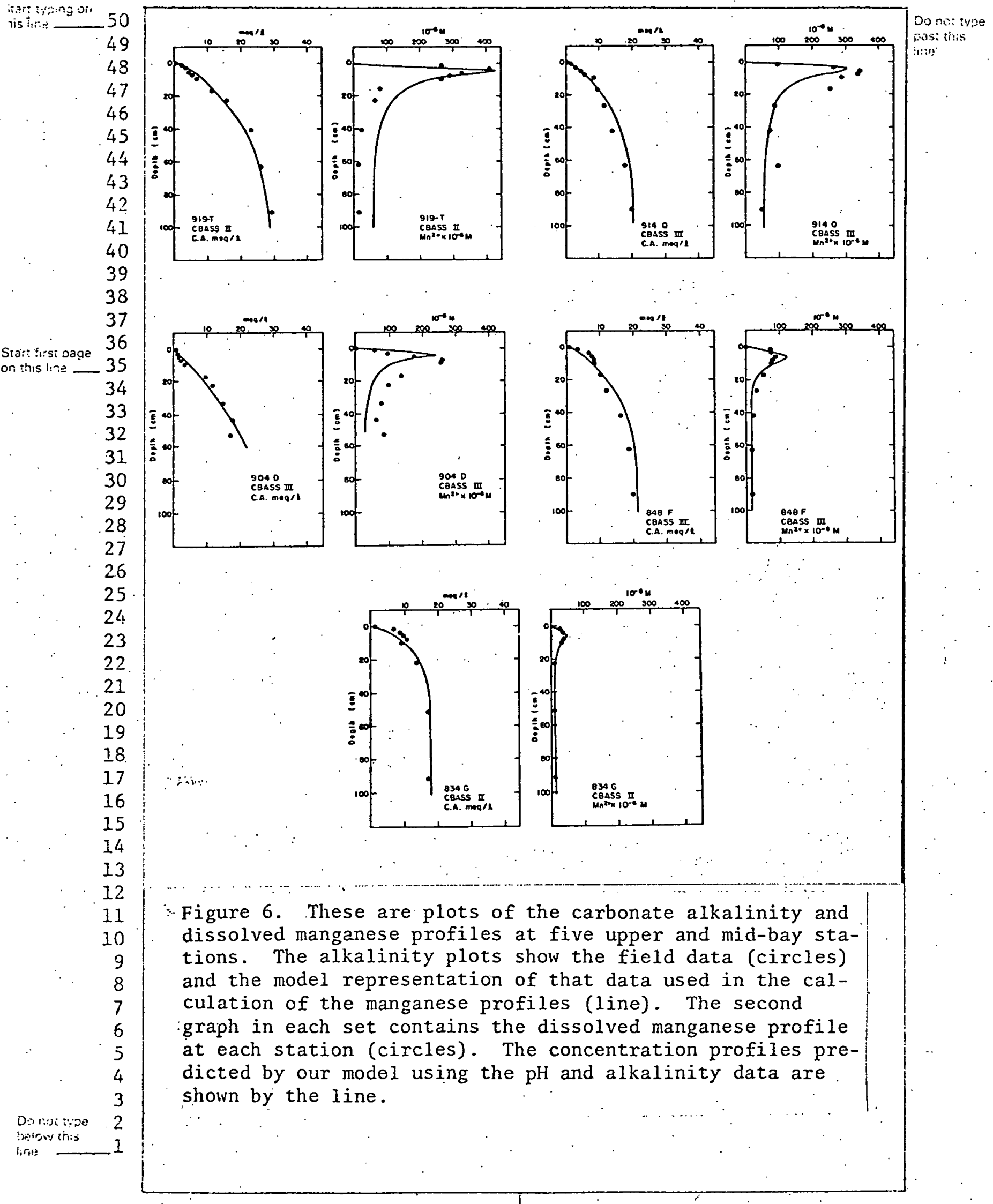




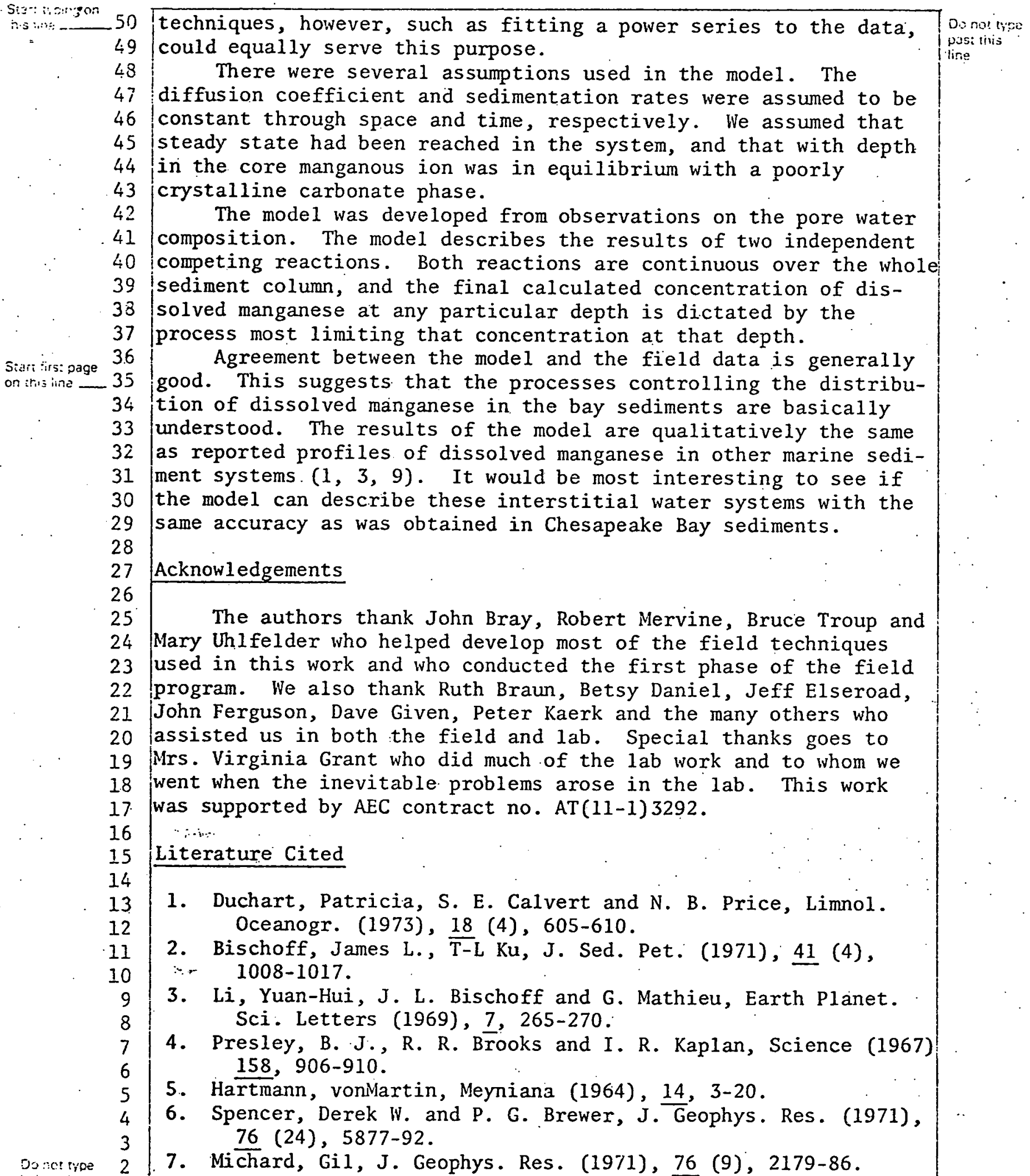

techniques, however, such as fitting a power series to the data, There were several assumptions used in the model. The diffusion coefficient and sedimentation rates were assumed to be constant through space and time, respectively. We assumed that in the core manganous ion was in equilibrium with a poorly crystalline carbonate phase.

The model was developed from observations on the pore water composition. The model describes the results of two independent competing reactions. Both reactions are continuous over the whole sediment column, and the final calculated concentration of dissolved manganese at any particular depth is dictated by the ss most limiting that concentration at that depth. Agreement between the model and the field data is generally good. This suggests that the processes controlling the distribution of dissolved manganese in the bay sediments are basically understood. The results of the model are qualitatively the same as reported profiles of dissolved manganese in other marine sediment systems. $(1,3,9)$. It would be most interesting to see if the model can describe these interstitial water systems with the same accuracy as was obtained in Chesapeake Bay sediments.

Acknowledgements

The authors thank John Bray, Robert Mervine, Bruce Troup and Mary Uhlfelder who helped develop most of the field techniques used in this work and who conducted the first phase of the field program. We also thank Ruth Braun, Betsy Daniel, Jeff Elseroad, John Ferguson, Dave Given, Peter Kaerk and the many others who assisted us in both the field and lab. Special thanks goes to Wrs. Virginia Grant who did much of the lab work and to whom we 3292

\section{Literature Cited}

1. Duchart, Patricia, S. E. Calvert and N. B. Price, Limnol. Oceanogr. (1973), 18 (4), 605-610.

2. Bischoff, James L., T-L Ku, J. Sed. Pet. (1971), 41 (4),

3. Li, Yuan-Hui, J. L. Bischoff and G. Mathieu, Earth Planet. Sci. Letters (1969), 7, 265-270.

4. Presley, B. J., R. R. Brooks and I. R. Kaplan, Science (1967)

5. Hartmann, vonMartin, Meyniana (1964), 14, 3-20.

7. Michard, Gil, J. Geophys. Res. (1971), 76 (9), 2179-86. 
S:3:: : ingon on mist.__ 50
8. Calvert, S. E. and N. B. Price, Earth Planet. Sci. Letters (1972), 16, 245-249.

9. Robbins, John A. and E. Callendar, Amer. J. Sci. (1975), accepted for publication.

10. Bender, Michael L., J. Geophys. Res. (1971), 76 (18), 42124215.

11. Anikouchine, William H., J. Geophys. Res. (1967), 72 (2), 505-509.

12. Lynn, D. C. and E. Bonatti, Mar. Geol. (1965), 3, 457-474.

13. Matisoff, Gerald, O. P. Bricker, G. R. Holdren Jr. and P. Kaerk, Proc. ACS-MARM Symposium, Mar. Chem. in the Coastal Environment, Philadelphia, Pa. (1975).

14. Reeburgh, William S., Limnol. Oceanogr. (1967) 12, 163-165.

15. Troup, Bruce N., 0. P. Bricker and J. T. Bray, Nature (1974), 249 (5454), 237-239.

16. Lerman, A. and B. F. Jones, Limnol. Oceanogr. (1973), 18 (1), 72-85.

17. Lerman, A. and R. R. Weiler, Earth Planet. Sci. Letters (1970), 10, 150-156.

18. Tzur, Y., J. Geophys. Res. (1971), 76 (18), 4208-4211.

19. Scholl, David W. and W. L. Johnson, 7th Int'l. Sedimentological Congr. (1967), Abstract.

20. Schubel, J. R., Beach and Shore (1968), April.

21. Carslaw, H. S. and J. C. Jaeger, "Conduction of Heat in Solids," $510 \mathrm{pp}$, Oxford Press, London, 1959.

22. U. S. Dept. of the Interior, Geological Survey, "Estimated Stream Discharge Entering Chesapeake Bay," Monthly Reports 1951- .

23. Manheim, F. T., Earth Planet. Sci. Letters (1970), 9, 307-309

24. Li, Yuan-Hui, and S. Gregory, Geochim. Cosmochim Acta (1974), 38, 703-714.

25. Garrels, R. M. and M. E. Thompson, Amer. J. Sci. (1962),

26.... Garreis, R.M. and C. L. Christ, "Solutions, Minerals, and Equilibria," 450 pp., Harper and Row, New York, 1965.

27. Wagman, D. D., W. H. Evans, V. B. Parker, I. Halow, S. M. Bailey, and R. H. Schumn, "Selected Values of Chemical Thermodynamic Properties," NBS-TN-270-4, 141 pp., U. S. Gov't. Printing Office, Washington, D. C., 1969.

28.". Crerar, David A., R. K. Cormick and H. L. Barnes, Acta Mineral. Petrogr. (1972), XX (2), 217-226.

29. Robie, R. A. and D. R. Waldbaum, U.S.G.S. Bul1. 1259, U. S. Gov't Printing Office, Washington, D. C., 1968 .

30. Bricker, 0. P. Amer. Mineral. (1965), 50, 1296-1354.

31. Berner, R. A., Geochim. Cosmochim. Acta (1964), 28, 1497-1503

32. Hurd, David C., Earth Planet. Sci. Letters (1972), 15, 411417.

33. Rickard, D. T., Amer. J. Sci. (1974), 274, 941-952. 